\title{
Deep Vein Valvular Incompetence: Options for Reconstruction
}

\author{
BRIDGET M. SANDERS, M.D., ${ }^{1}$ and MICHAEL C. DALSING, M.D. ${ }^{1}$
}

ABSTRACT Some degree of lower limb chronic venous insufficiency (CVI) affects over 30 million Americans. Varicosities have been recognized since 1500 в.C.; however, an accurate diagnosis of the variety of lower limb venous diseases and their treatment has made steady headway only in the recent past. Superficial and perforator insufficiency can be eliminated by a multitude of extirpative techniques. CVI due to advanced deep venous abnormalities is more problematic. Surgical intervention has become an option for end-stage patients who have failed conservative medical therapy. Direct in situ valve repairs are possible by a variety of methods. Secondary causes of valve damage can be corrected by transposition or transplant techniques. Many of these deep venous reconstructions can be supported by long-term data not available even 20 years ago. A quest for valve substitutes for patients with no native valves available for transplantation continues. Yet long-term follow-up with a precise gradation of improvement in signs, symptoms, and diagnostic studies is essential for continued growth in the field of deep venous reconstructions.

Keywords Chronic venous insufficiency, venous surgery, deep venous disease

Lower limb chronic venous insufficiency (CVI), to some degree, affects over 30 million Americans, with women accounting for greater than half of the cases. $^{1,2}$ Of those suffering from CVI, up to $2 \%$ experience complications

Perspectives in Vascular Surgery and Endovascular Therapy, Volume 14, Number 1, 2001. Address for correspondence and reprint requests: Michael C. Dalsing, M.D., Division of Vascular Surgery, Indiana University School of Medicine, 1001 West 10th Street, Indianapolis, IN 46202. 'Department of General Surgery, Division of Vascular Surgery, Indianapolis, IN. Copyright (C) 2001 by Thieme Medical Publishers, Inc., 333 Seventh Avenue, New York, NY 10001, USA. Tel: +1(212) 584-4662. 1531-0035,p;2001,14,01,089,106,ftx,en;pvs00109x. 
associated with lower extremity venous ulcerations. ${ }^{2,3}$ Varicosities have been recognized since 1500 B.C.; however, an accurate diagnosis of the variety of lower limb venous diseases has made steady progress only recently. ${ }^{4}$ Effective surgical intervention has become an option for the treatment of these patients as a result of this improved diagnostic accuracy. Superficial venous incompetence can be eliminated by functionally removing the incompetent saphenous system by a number of techniques. The proper management of perforator insufficiency is controversial; however, the era of minimally invasive surgery provides a new, less traumatic approach to the care of these patients. CVI due to advanced deep venous abnormalities is more problematic. However, a variety of reconstructive surgeries are available to correct an insufficient lower limb deep venous system and are now supported by longterm data not available even 20 years ago.

Worsening patient symptoms are the driving force behind any aggressive intervention. Noninvasive diagnostic studies provide a firm foundation with which to differentiate superficial, perforator, or deep venous disease. The treatment of superficial and perforator disease may only require that level of diagnostic support. Preoperative invasive studies such as ascending and descending venography are often necessary to provide the precise anatomical clarity needed to plan a surgical approach in patients with chronic deep venous insufficiency (CDVI).

\section{PATHOPHYSIOLOGY}

Two basic pathologic processes account for CVI and both may occur in the same patient. 5 Primary venous insufficiency results from an inherent structural abnormality within the valve cusps or within the vein wall. ${ }^{6}$ Floppy, elongated cusps or diameter dilation prevent proper coaptation of the valve edges in either case. Reflux of blood occurs when a pressure gradient is created, such as with standing. Because a valve is present and structurally intact, an in situ repair can be undertaken to eliminate valve malalignment and thereby prevent retrograde blood flow during periods of stress. Secondary venous insufficiency, often occurring after an attack of deep venous thrombosis, is another major contributor to CVI. It may account for 40 to $70 \%$ of cases presenting as a major insufficiency within the deep venous valvular system. ${ }^{7,8}$ Thrombosis and inflammation lead to scar formation that can foreshorten and damage the valve cusps and cause lumenal narrowing. The overall result is a valve mechanism so severely damaged that an in situ repair is impractical. Transposition of an incompetent lower limb axial system to a location below a competent venous valve or transplantation of a competent valve structure into an incompetent deep venous system are two options available for correction of secondary valvular insufficiency. 


\section{DIAGNOSIS}

The accurate classification of venous disease is essential to its proper evaluation and management. Limbs with chronic venous disease should be classified using the CEAP system as detailed in Table 1.9 The CEAP system denotes a clinical (C), etiologic (E), anatomic (A), and pathophysiologic (P) classification and is the most current classification schema available. ${ }^{9}$ The clinical components are described in detail in Table 2, and each component is further defined with a subscript of $\mathrm{A}$ for asymptomatic or $\mathrm{S}$ for symptomatic disease. ${ }^{9}$ The etiology can be congenital (C); primary (P), signifying no known cause; or secondary $(\mathrm{S})$, signifying a known cause such as deep venous thrombosis (DVT). Anatomic classifications are basically divided into superficial (S), perforating (P), and/or deep (D) disease. Each anatomic system can be further divided by each named vein and by the pathologic process involved. Pathologic classifications are reflux $(\mathrm{R})$, obstruction $(\mathrm{O})$, or both. Patients with severe symptoms requiring deep venous valvular reconstruction are usually within the $\mathrm{C}_{5 \text { or } 6, S} \mathrm{E}_{\mathrm{C} \text { or } \mathrm{P} \text { or } S} \mathrm{~A}_{\mathrm{D}} \mathrm{P}_{\mathrm{R}}$ classification, although patients with less severe disabling symptoms are occasionally considered candidates. Clinical outcome after surgery can be categorized by guidelines suggested by the reporting standards in venous disease, as outlined in Table 3.10 An active effort to improve an outcome scoring system is underway. The hope is to provide a precise gradation of changes in signs, symptoms, and diagnostic studies with which to compare interventional therapies. Only by being able to compare patients and the results of treatments can we hope to improve our care of this patient population.

For most routine evaluations, the diagnostic interrogation of the venous system begins with a venous Duplex ultrasound study to help distinguish reflux from obstructive disease, to identify the extent of involvement, and to eliminate patients with isolated superficial or perforator reflux from undergoing superfluous invasive testing. Reflux of blood past a deep venous valve, following a graded rapid cuff compression and release, which lasts longer than $0.5 \mathrm{sec}$ (a determination of valve closure time), is considered abnormal.11 Others use $1.0 \mathrm{sec}$ as the separation between a normal and abnormal

Table 1 CEAP Classification of Chronic Lower Extremity Venous Disease

C Clinical signs (grades 0-6), supplemented by A for asymptomatic and S for symptomatic presentation

E Etiologic classification (Congenital, Primary, Secondary)

A Anatomic distribution (Superficial, Deep, or Perforator, alone or in combination)

P Pathophysiologic dysfunction (Reflux or Obstruction, alone or in combination) 
Table 2 Clinical Classification of Chronic Lower Extremity Venous Disease

Class $0 \quad$ No visible or palpable signs of venous disease

Class 1 Telangiectases, reticular veins, malleolar flare

Class 2 Varicose veins

Class 3 Edema without skin changes

Class 4 Skin changes ascribed to venous disease (e.g., pigmentation, venous eczema, lipodermatosclerosis)

Class 5 Skin changes as defined above with healed ulceration

Class 6 Skin changes as defined above with active ulceration

valve closure time when manual calf compression is the stimulus to blood flow. ${ }^{12}$ Air plethysmography or other hemodynamic tests assess the physiologic status of the leg by evaluating venous emptying, refilling, and the efficiency of the calf muscle pump. ${ }^{13,14}$ One or the other physiologic and hemodynamic tests, in addition to a duplex venous study, provides an overall picture of venous performance in addition to critical anatomic information.

The patient determined to have major deep venous disease as the cause of their symptoms requires precise venographic study to plan a surgical approach. Ascending venography delineates precise deep venous anatomy, eliminates obstruction as a component factor, and confirms noninvasive hemodynamic studies by measuring lower extremity venous pressures during exercise and as compared with upper extremity pressures. ${ }^{15,16}$ Descending venography identifies valve structural integrity and location (Fig. 1) as well as the degree of overall reflux. ${ }^{17}$ Patients with grade 3 or 4 reflux, retrograde flow below the popliteal vein with Valsalva maneuver (Fig. 2), are deemed to

Table 3 Clinical Outcome after Surgery

+3 Asymptomatic, no symptoms of chronic venous disease, improvement of VRT to normal or at least $+5 \mathrm{sec}$, improvement in AVP to normal or at least -10 torr

+2 Moderate improvement, mild symptoms of chronic venous disease, improvement of VRT to normal or at least $+5 \mathrm{sec}$, improvement in AVP to normal or at least -10 torr

+1 Mild improvement, clinical improvement or improvement in vascular laboratory tests (VRT or AVP)

0 Unchanged, no worse clinically or by vascular laboratory test results

-1 Mild worsening; worsening of symptoms of chronic venous disease or vascular laboratory tests (VRT or AVP)

-2 Significant worsening, worsening of symptoms and worsening of vascular laboratory test results (VRT or AVP)

-3 Marked worsening, same as -2 accompanied by either new or worsening ankle claudication

VRT, venous refilling time; AVP, ambulatory venous pressure 


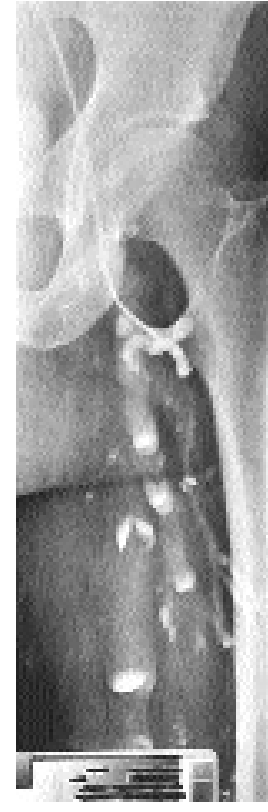

A

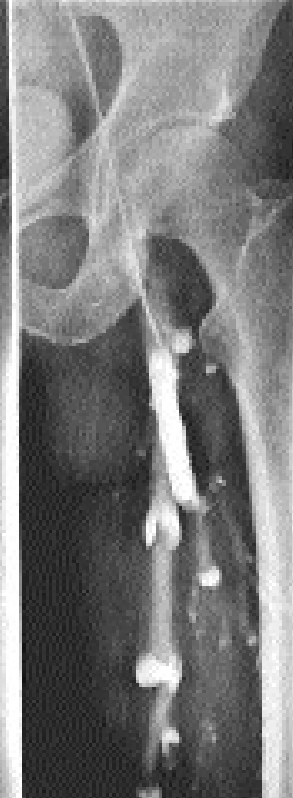

B

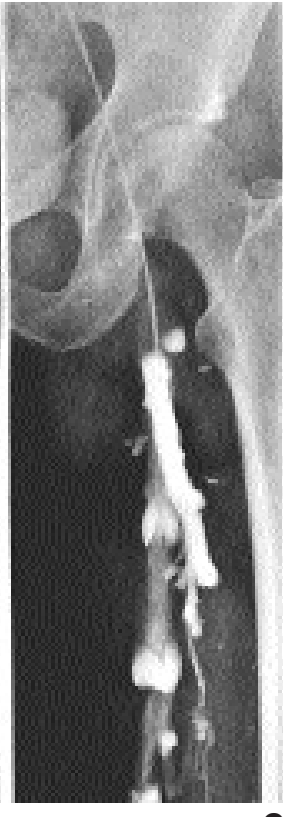

C

Fig. I This descending venogram is presented in reverse chronological order to highlight the appearance of valve structures after an injection of contrast with the leg at rest and without a Valsalva maneuver. On early injection (panel C), the contrast is carried down the leg because it is heavier than blood. Because the leg is at rest and devoid of a pressure gradient, the valves are partially open such that the contrast forms an outline of the valve cusps as it cascades down the leg. Panel (B) is at a slightly later stage whereas panel (A) clearly demonstrates the valve cusps just prior to leg movement, which will flush the contrast from the leg.

have a significant and pathologic deep venous reflux. A determination of the reflux status of the profunda femoris vein (PFV) is of utmost importance in planning reconstruction. Repair of a proximal superficial femoral vein (SFV) may suffice if the PFV system is competent. ${ }^{18-20}$ If the PFV is incompetent, both the SFV and PFV reflux must be addressed or the popliteal vein must be made competent to prevent reflux from both cephalad systems. 5,21

\section{SURGICAL REPAIR}

Patients with superficial axial reflux and varicose veins can be treated with saphenous vein high ligation and stripping in addition to branch varicosectomy. Alternative approaches using sclerotherapy or minimally invasive techniques may also be appropriate in select cases. Perforator incompetence causing venous hypertension can be addressed by ligation and/or division of the involved perforating veins via an open or subfacial endoscopic perforator surgery (SEPS) technique. If these problems coexist with deep venous reflux, 


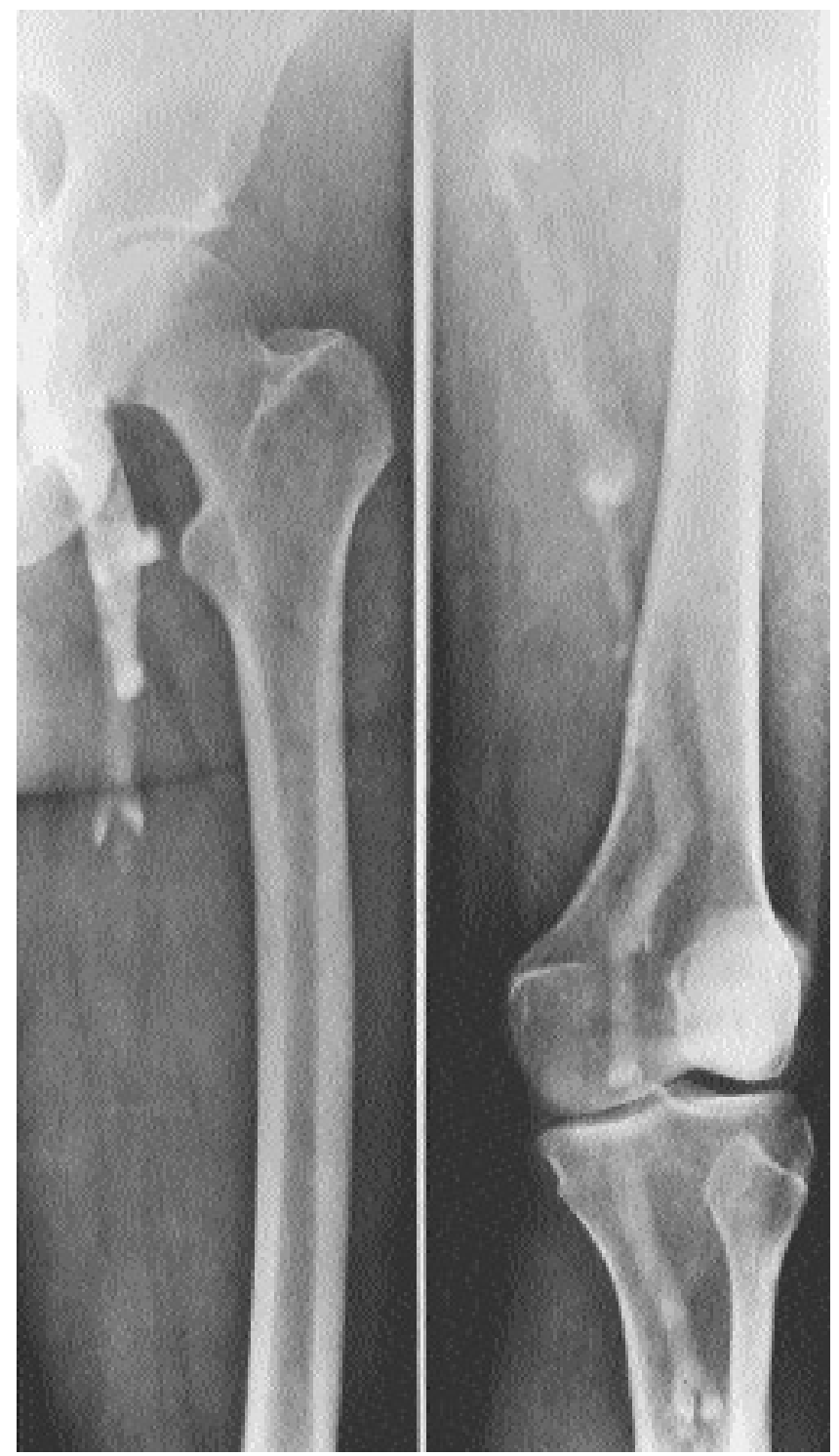

Fig. 2 In this descending venogram, the patient is performing a Valsalva maneuver during contrast injection. Although valves are present in this patient with primary venous valvular insufficiency, the valves do not prevent retrograde blood flow. Refluxing blood reaches the calf suggestive of at least a grade 3 degree of reflux. 
they are often corrected prior to an aggressive repair of the incompetent deep venous valvular system.

\section{Internal and Minimally Invasive Valvuloplasty}

Primary venous valvular reflux can be corrected by a direct in situ repair utilizing an open valvuloplasty or via more minimally invasive techniques, such as an external sleeve or banding, external valvuloplasty, or angioscopicassisted valvuloplasty. The open direct method has been performed with a transcommissural (Kistner 1968), supracommissural (Raju 1983), or supra-T commissural (Sottiurai 1988) approach (Figs. 3 through 5). ${ }^{22-24}$ Common to all three methods is precise suturing performed under direct vision to properly reef the elongated cusp leaflets. Technically, it appears that plication of

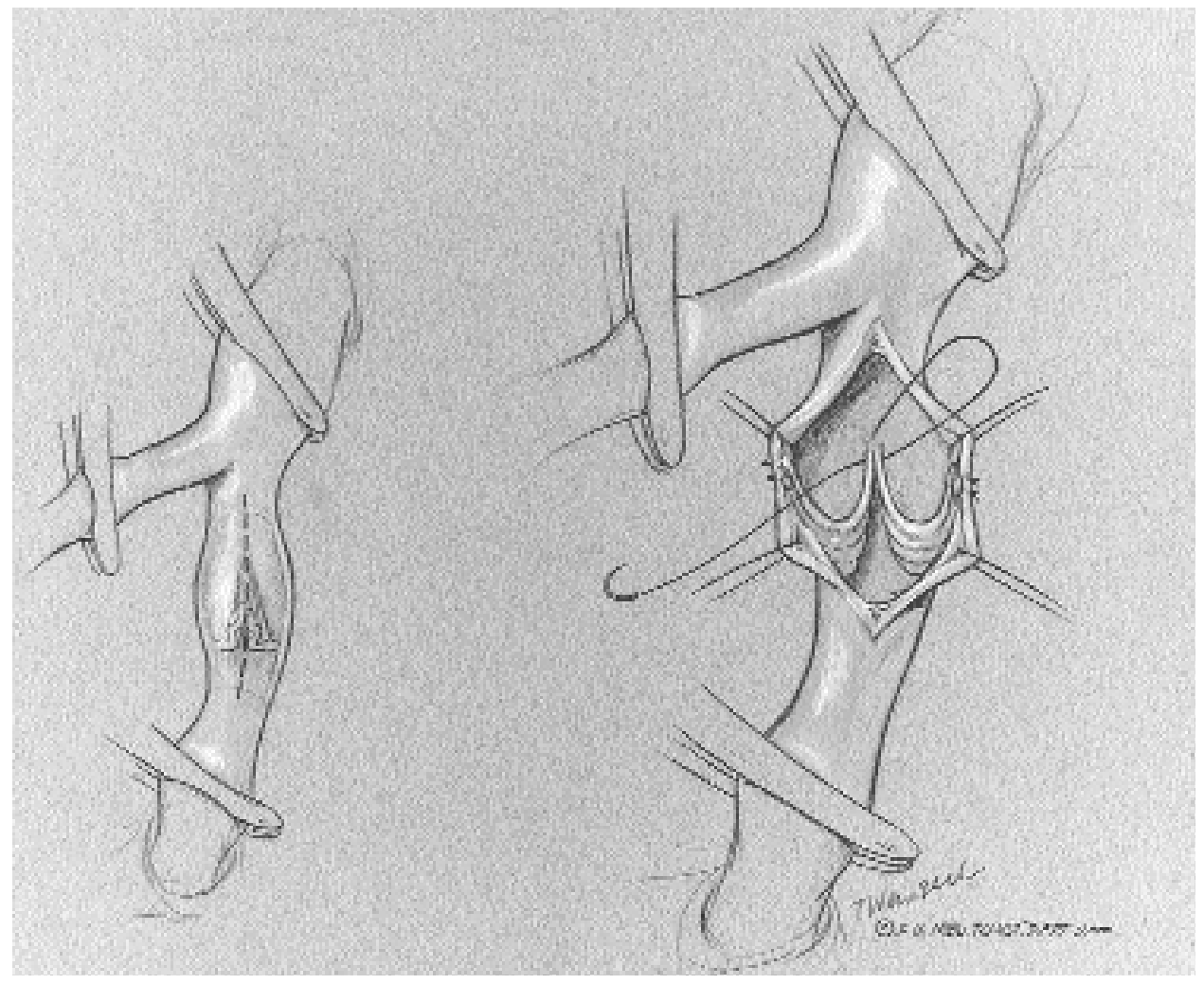

Fig. 3 The Kistner transcommissural approach allows for visualization of the venous valves. Care must be taken to prevent damage to the valve cusps during the longitudinal venotomy. The transcommissural incision as well as the valve undergoing repair are pictured. (From Nachreiner RD, Bhuller AS, Dalsing MC. Surgical repair of incompetent venous valves. In: Handbook of Venous Disorders, 2nd ed. London: Arnold Publishing; 2000; with permission.) 


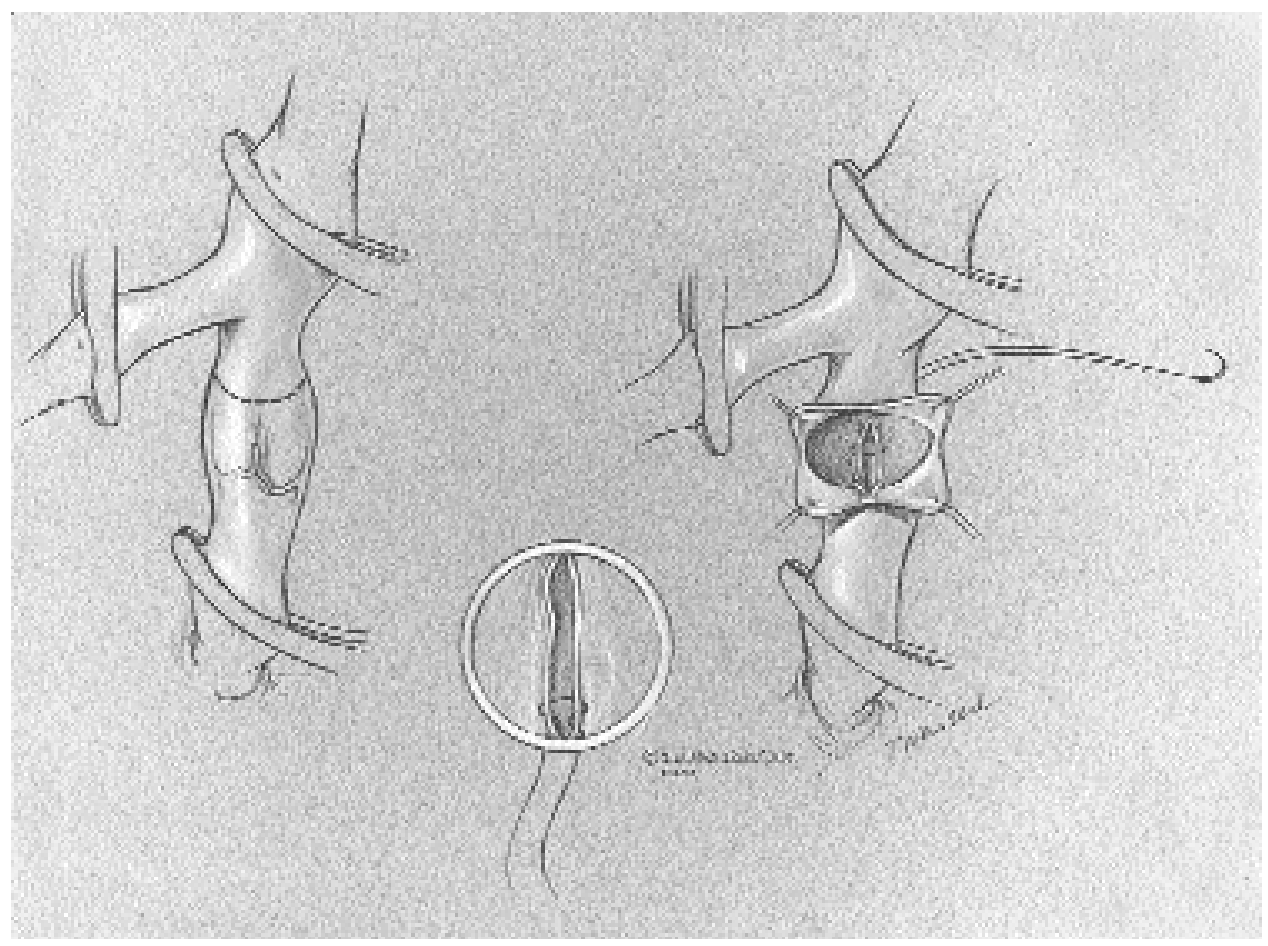

Fig. 4 The Raju supracommissural approach minimizes the potential of valve cusp damage but sacrifices some of the excellent exposure afforded by the transcommissural approach. Illustrated is the valve structure during incision and valvuloplasty. (From Nachreiner RD, Bhuller AS, and Dalsing MC. Surgical repair of incompetent venous valves. In: Handbook of Venous Disorders, 2nd ed. London: Arnold Publishing; 2000; with permission.)

$20 \%$ of the leaflet length generally results in a competent valve. ${ }^{25}$ Competency rates of approximately $70 \%$ have been reported at 5 years of follow-up and clinical results ranked as good to excellent are maintained if valve competency exists. $8,20,22$

Fashioning of an external sleeve or band to reduce the vein diameter, thus reestablishing proper cusp apposition, functions well in patients whose valve is spontaneously competent following dissection vasospasm..$^{25,26}$ Banding involves wrapping of synthetic or autogenous material around the circumference of the short venous segment encompassing the valve structure (length approximately 2 to $3 \mathrm{~cm}$ ). The band is tightened until valve competence is maintained, then fastened to itself and the venous adventicia to prevent migration. There is a commercial banding device currently under investigation. One-year follow-up of 14 patients using this device in the saphenous system revealed absent reflux, patent veins, and mobile cusps. ${ }^{27}$ Additionally, 


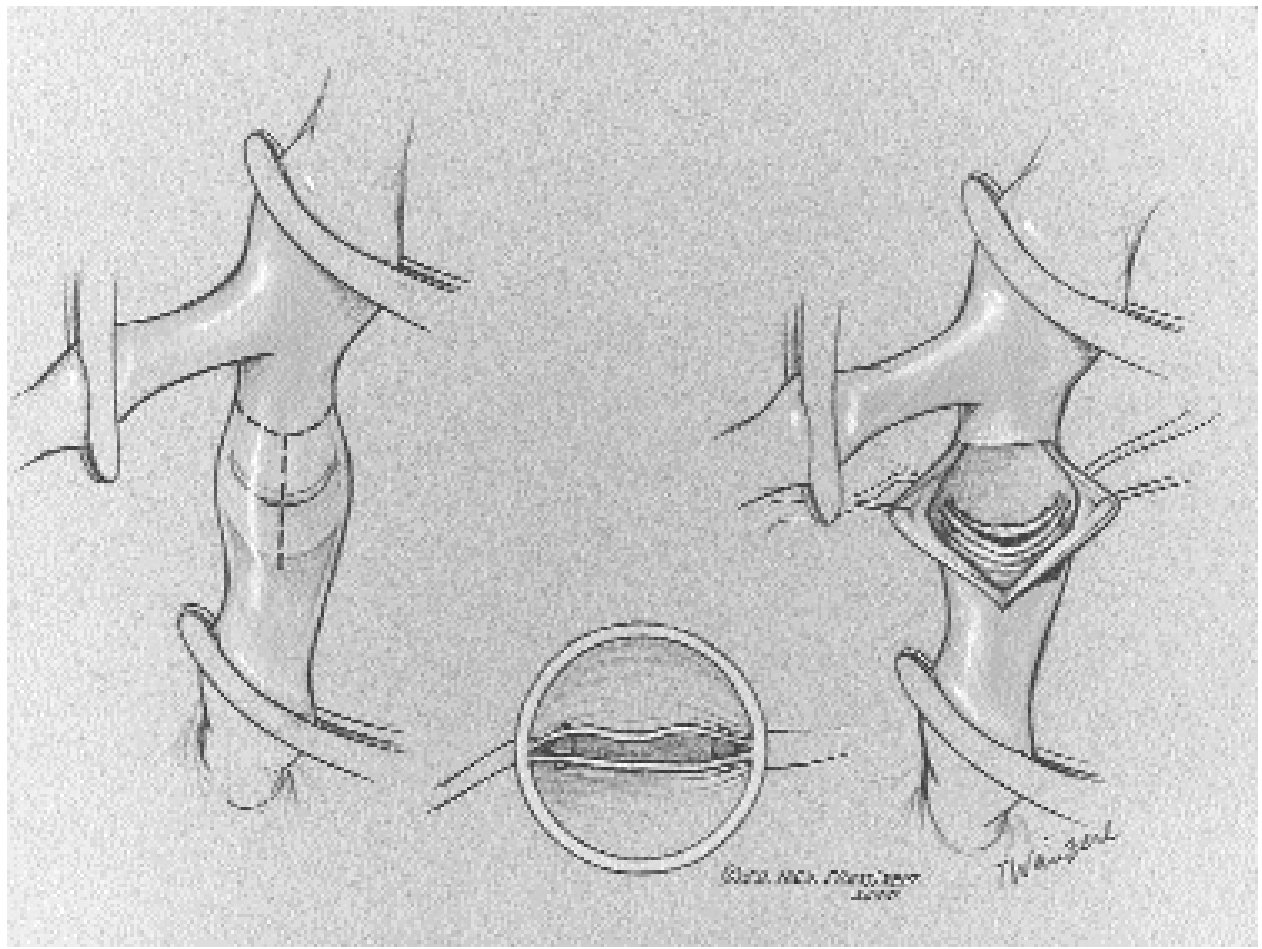

Fig. 5 The Sottiuri supra-T commissural approach improves the visualization of the valve mechanism by extending the supracommissural incision parallel to the vein in a "T" shape. (From Nachreiner RD, Bhuller AS, and Dalsing MC. Surgical repair of incompetent venous valves. In: Handbook of Venous Disorders, 2nd ed. London: Arnold Publishing; 2000; with permission.)

banding can be utilized during other valve reconstructions to avoid delayed wall dilation.

External valvuloplasty was introduced by Kistner in 1990 (Fig. 6).28 External valvuloplasty requires suture placement from outside of the vein lumen aimed at tightening the commissural angle. Some preliminary evidence suggests that the less precise anatomic repair afforded by this method results in a less durable repair. ${ }^{20} \mathrm{~A}$ modification using a limited anterior plication approach, in addition to saphenous stripping, demonstrated lower ambulatory venous pressures and improved venous refill time even after 10 years of follow-up. ${ }^{29}$ This was a study performed in patients with less than a $\mathrm{C}_{5 \text { or } 6}$ classification being performed for severely symptomatic varicose veins. It did, however, demonstrate the improved hemodynamic results possible with external valvuloplasty.

Gloviczki reported angioscopic-assisted valvuloplasty in 1991. ${ }^{30}$ An angioscope is introduced through a side branch and advanced into the vein proper 


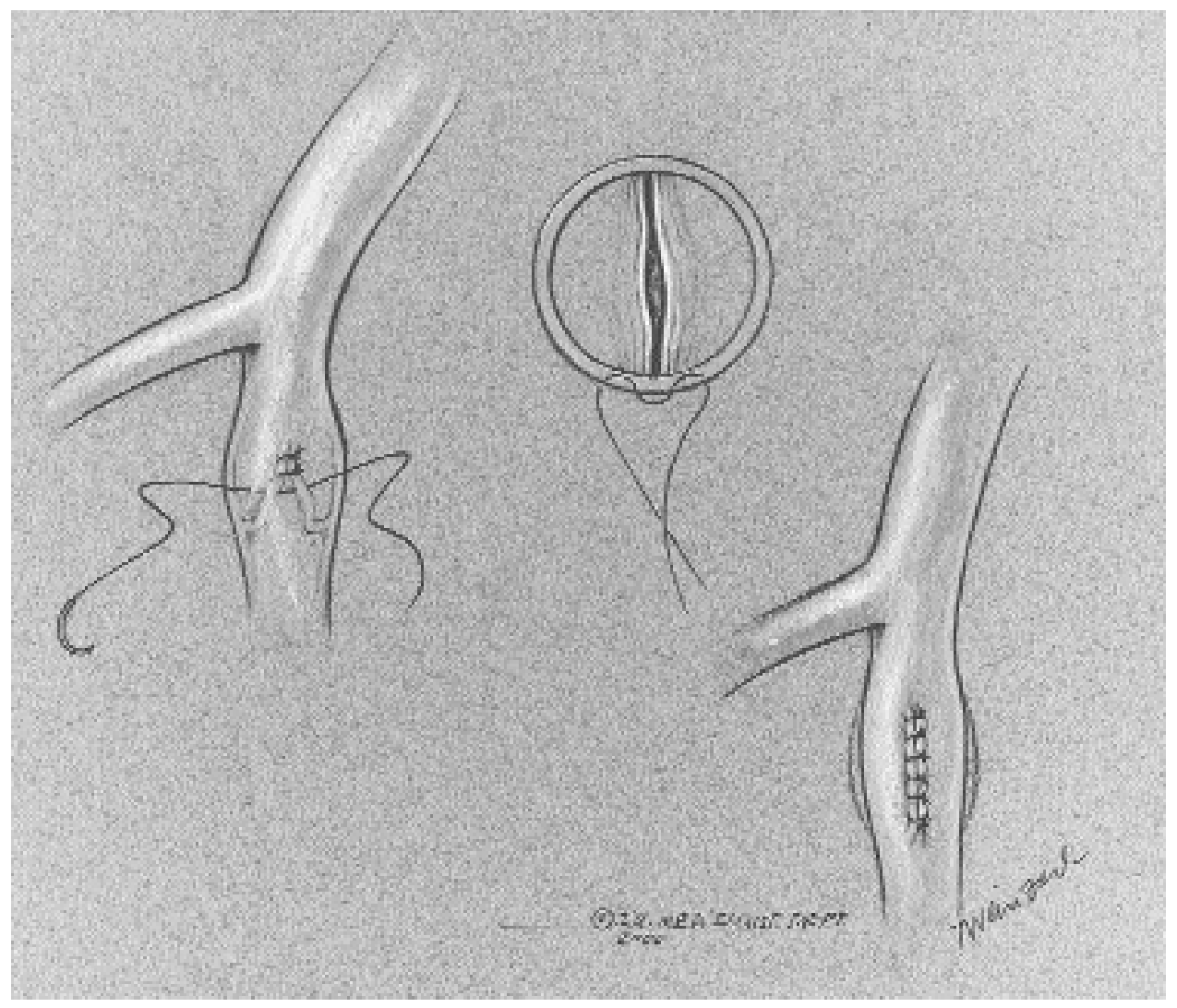

Fig. 6 External valvuloplasty eliminates the need for venotomy. External suture placement is aimed at tightening the commissural angle. (From Nachreiner RD, Bhuller AS, Dalsing MC. Surgical repair of incompetent venous valves. In: Handbook of Venous Disorders, 2nd ed. London: Arnold Publishing; 2000; with permission.)

directly above the incompetent valve (Fig. 7). This method allows direct intraluminal suture repair of the valve cusps without opening the vein. This approach does require anticoagulation because blood flow interruption is mandatory to allow heparin flushing of the vein lumen for optimal optical clarity.

Internal valvuloplasty appears to be the most precise and durable repair for primary valvular incompetence. In a retrospective study reported by Raju in 1996, the durability of 316 valve reconstructive procedures was evaluated by venous duplex scanning. ${ }^{20}$ Internal valvuloplasty was the most durable, with external banding ranked second. Patients undergoing external valvuloplasty experienced earlier and more frequent recurrence of venous reflux. Angioscopic-assisted valvuloplasty was insufficiently represented to allow adequate evaluation. 


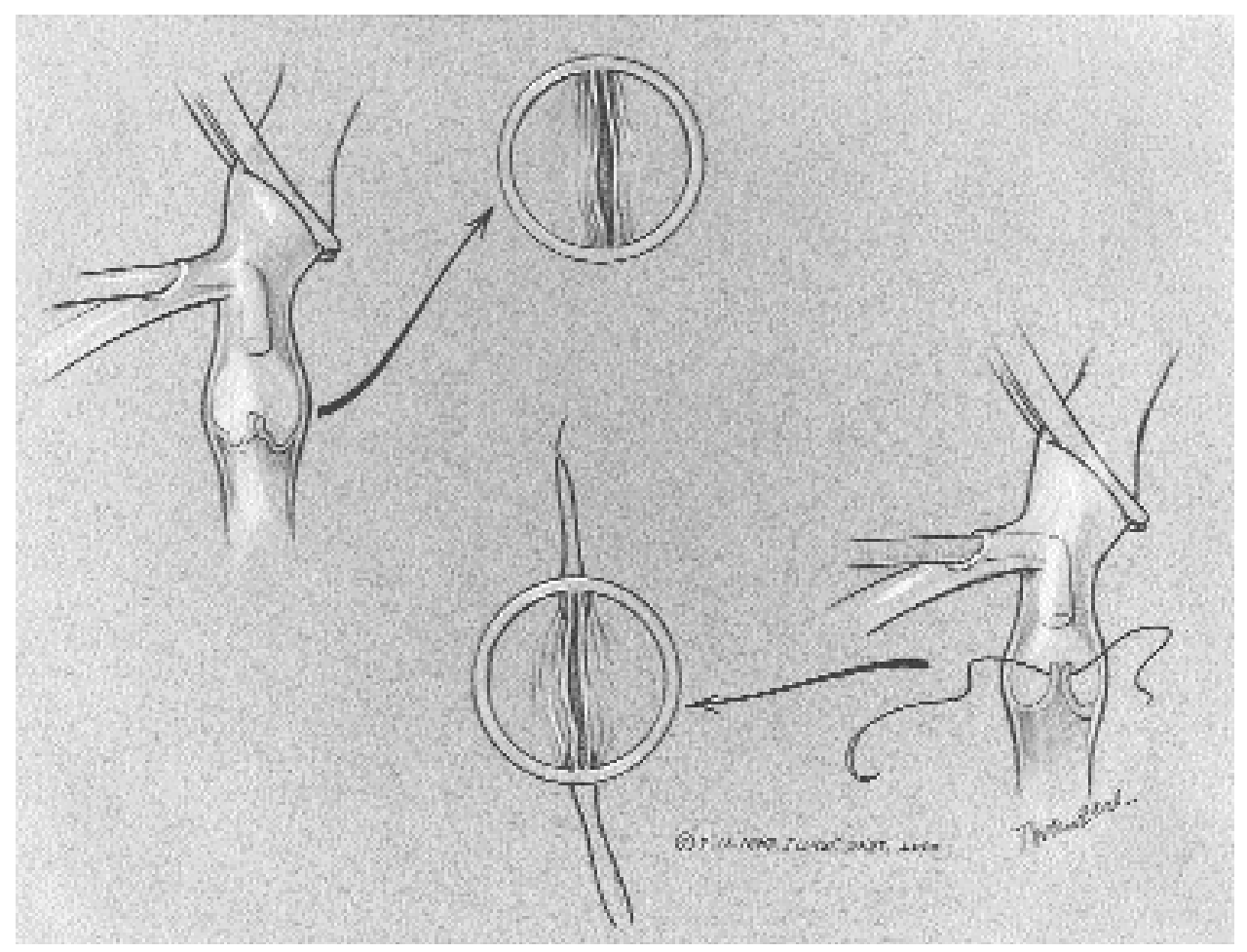

Fig. 7 Angioscopic-assisted valvuloplasty allows for direct visualization of the incompetent valve anatomy assisting precise suture placement. The scope is advanced through a side branch and positioned above the valve. (From Nachreiner RD, Bhuller AS, and Dalsing MC. Surgical repair of incompetent venous valves. In: Handbook of Venous Disorders, 2nd ed. London: Arnold Publishing; 2000; with permission.)

Primary valve repair is generally well tolerated with low complication rates and essentially no mortality in a majority of reported series. ${ }^{31}$ Postoperative hematoma and/or seroma complications were noted in up to $15 \%$ of cases, depending on the level of anticoagulation required.5,25,32,33 Deep venous thrombosis, always a grave concern following venous valve surgery, was observed in less than $10 \%$ of all patients reviewed.5,25,32,33 Wound infections were noted in 2 to $4 \%$ of patients. 5,25

\section{Valve Transposition}

Deep venous valvular insufficiency due to events such as the postthrombotic syndrome is technically challenging. Valvuloplasty is not an option because the inflammation that accompanies thrombosis and recanalization damages the surrounding venous cusp and the vein wall. If the reflux spares 
a single axial venous system, then the incompetent systems can be transposed to below a competent valve. This unusual situation occurs in 2 to $3 \%$ of patients with chronic deep vein insufficiency. The most common circumstance involves SFV reflux in the face of a competent PFV valve. The SFV is ligated distal to its junction with the CFV and implanted distal to the competent valve lying within the PFV (Fig. 8). Other less common scenarios include anastomosis of the SFV below a competent valve within the greater saphenous vein (GSV) or an incompetent PFV to below a competent SFV or GSV valve. Venous valve transposition provides good to excellent clinical outcomes in 40 to $50 \%$ of patients followed for 5 years. ${ }^{5,31}$

\section{Valve Transplantation}

Venous valve transplantation is another surgical option available for the postthrombotic syndrome. Valvular transplantation requires placement of an upper extremity vein containing a competent valve (or one that could be

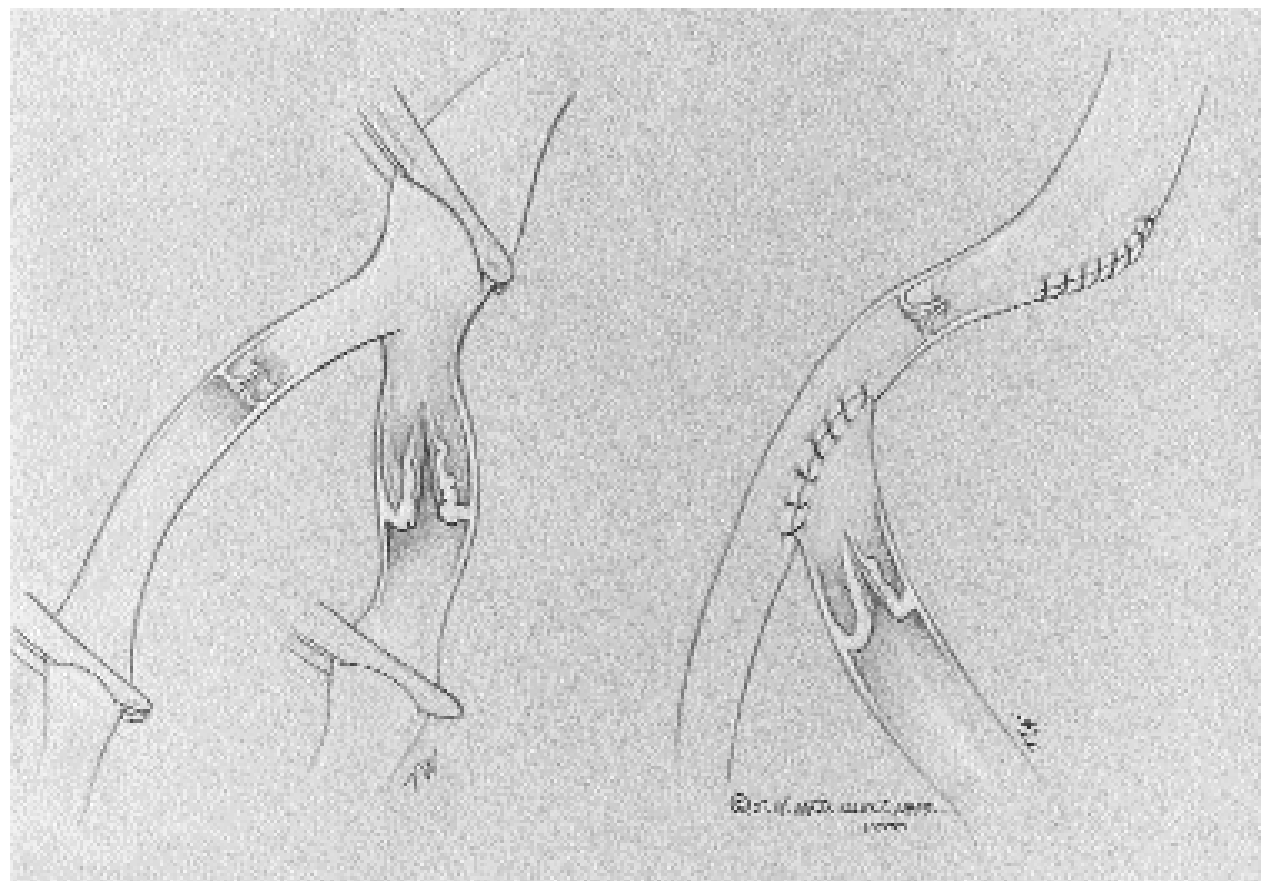

Fig. 8 Transposition of the superficial femoral vein (SFV) after ligation distal to its junction with the common femoral vein (CFV) involves implantation of the truncated SFV distal to a competent valve lying within the profunda femoral vein (PFV). (From Dalsing MC, Nachreiner RD, Bhuller A. Role of Venous Valvular Surgery in Chronic Venous Insufficiency in Vascular Surgery-Year 2000. New York: McGrawHill; 2000; with permission.) 
made competent) into the incompetent lower limb venous system. In 1982, Taheri described the first successful valve transplantation in humans. ${ }^{34}$ In the original description, a 2 - to 3 -cm segment of axillary vein, including a competent valve, was harvested. This segment was transplanted to replace part of the SFV just distal to its junction with the PFV. Figure 9 provides an artist's re-creation of a harvest of an axillary vein segment containing a competent venous valve. Figure 10 shows a valve transplant with the cephalad anastomosis completed and the obviously competent valve preventing retrograde blood flow. The recipient location for valve transplantation depends on the competence status of the femoral veins (profunda and superficial) and surgeon preference. ${ }^{5,18-21,35}$ This approach has potential problems, which include the absence of a functional upper extremity venous valve (up to $40 \%$ ) and deterioration of the valve with time. ${ }^{20,23,25}$ Delayed dilation with resulting cusp valvular reflux may be anticipated and potentially prevented by wrapping the transplant segment with an external band. Posttransplant,

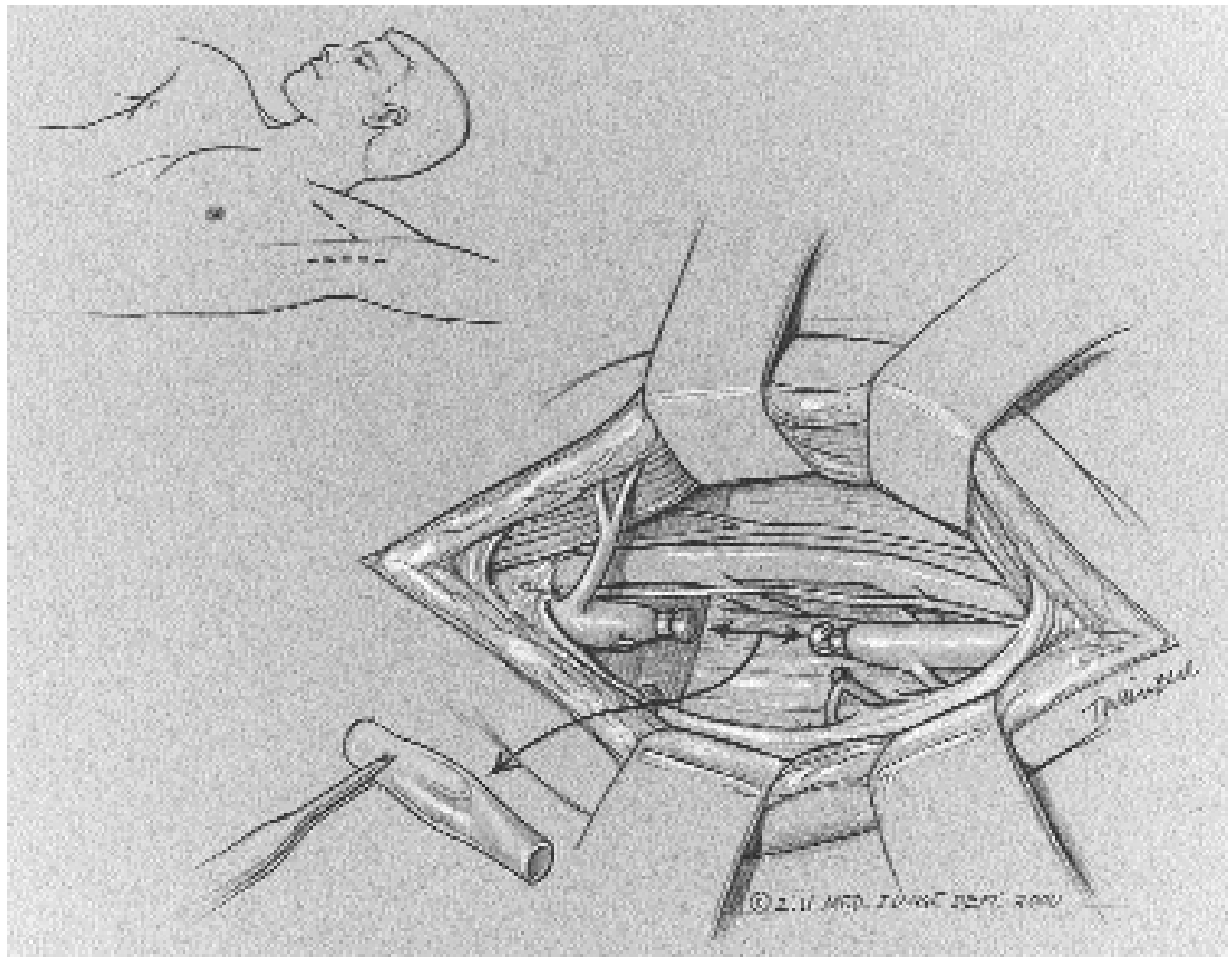

Fig. 9 Transplantation can be performed by harvesting an axillary venous segment containing a competent valve or a valve that has been made competent by valvuloplasty. (From Dalsing MC. Chronic venous disease. In: LJ Greenfield et al., eds. Surgery: Scientific Principle and Practice, 3rd ed. Philadelphia: Lippincott, Williams, \& Wilkins; 2001: p. 23; with permission.) 


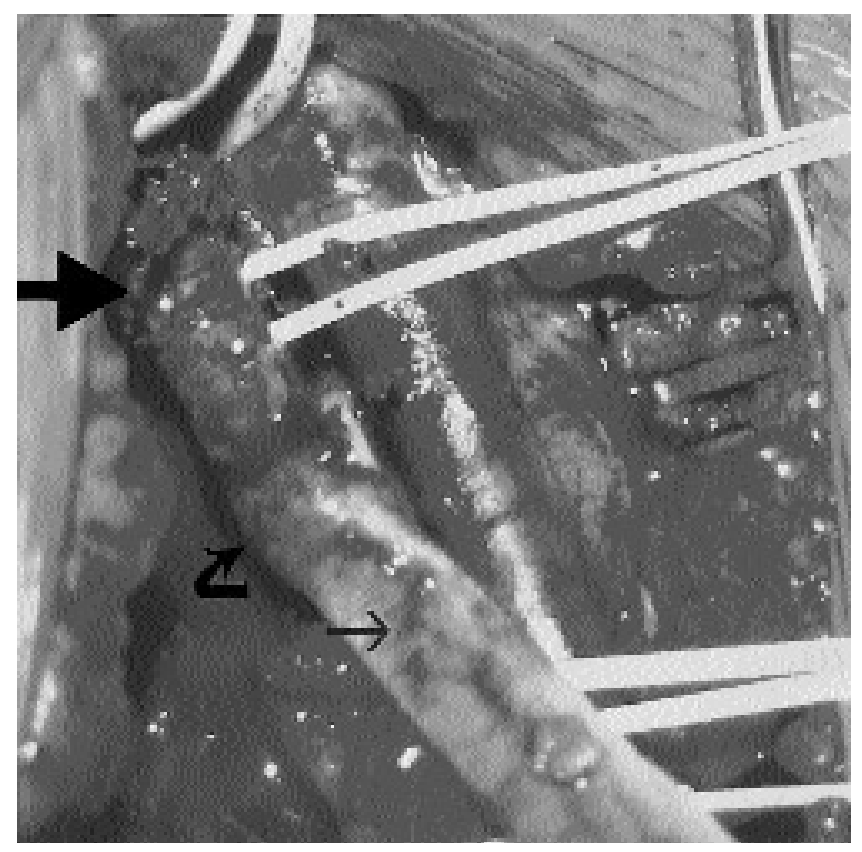

Fig. 10 An intraoperative photograph of a valve transplantation in which the proximal anastomosis has been completed (large arrow) with an interrupted technique. Proximal control has been released and the competent valve (curved arrow) prevents retrograde bleeding. A flat, nondistended distal vein segment is noted (small arrow). The distal anastomosis can be preformed, often without a proximal clamp present, after proper trimming of the donor vein segment.

approximately $50 \%$ or more of patients will be clinically improved even at 5 years, with a similar percentage having a competent valve. ${ }^{25,31,35}$ Sitespecific complications such as hematoma and/or seroma formation and wound infections are comparable to that reported for primary valve repair, with an added potential for complications occurring at the upper extremity vein harvest site.

\section{Venous Sling}

Psathakis originally described a gracilis or semitendinous tendon sling designed to produce an external valvelike mechanism in 1964.36 This procedure was augmented with a polymeric silicone tendon in $1980 .{ }^{36}$ The tendon sling has been reported to produce clinical improvement in venous hemodynamics postoperatively. ${ }^{37}$ This technique has not been widely adopted in the United States, possibly because of the difficulty in determining proper tension on the sling intraoperatively and the lack of confirmatory data from other venous centers. 


\section{Experimental Venous Valve Substitutes}

There has been an active quest to find a valve substitute for patients who lack a native valve for transplantation. Autologous reconstructed valves have met with some experimental success. An Eiseman/Malette-type venous valve maintained adequate patency but was less hemodynamically responsive than a native valve. ${ }^{38}$ This is an invagination of a vein within itself to create a bicuspid valve mechanism. A modification involving stripping of the invaginated adventicia resulted in a thinner valve, but clotting difficulties were experienced. ${ }^{39}$ Clinically, Raju has fully constructed a bicuspid valve within the lower leg venous system using adventicia-stripped upper extremity vein. Only seven have been reported to date with acceptable clinical results ( 5 of 7 healed an active ulcer within 4 months). All remained patent during a 15-to 24-month period of follow-up. ${ }^{40}$ Plagnol et al. reported on 20 clinical reconstructions using an invaginated greater saphenous vein stump to construct a common femoral vein bicuspid valve. ${ }^{41}$ Duplex imaging demonstrated only one case of mild reflux with a mean follow-up of 10 months. Lack of confirmatory studies, small patient numbers, and a limited candidate group make it difficult to determine the long-term impact of these autologous alternatives.

Fresh and glutaraldehyde-preserved allografts, synthetic polymer, and titanium valve devices have all failed in canine trials. ${ }^{42-45}$ A preliminary report of ongoing work describing a successful venous valvular reconstruction utilizing a bovine monocusp patch in both the SFV and GSV has been described with hemodynamic and clinical improvement after a 15-month follow-up. ${ }^{46}$ Cryopreserved venous allografts studied in an experimental model showed promising results. ${ }^{47} \mathrm{~A}$ recent phase I clinical trial of cryopreserved human allograft venous valves reported a $67 \%$ primary graft patency and $56 \% \mathrm{com}$ petency rate at 6 months. ${ }^{48}$ The study consisted of nine patients having a single valve transplant placed distally to all lower extremity venous reflux. ${ }^{48}$ In a second trial, an approximately $50 \%$ competency rate was reported at 1 year. ${ }^{49}$ No long-term follow-up is currently available.

\section{CONCLUSION}

Surgical reconstruction for chronic deep venous insufficiency must start with a careful and thorough diagnosis of properly selected patients with disabling disease. For primary deep venous reflux, internal valvuloplasty remains the best option, with good to excellent results in up to $70 \%$ of patients. For disease secondary to problems such as the postthrombotic syndrome, valve replacement by either transposition or transplantation is acceptable, with significant improvement of symptoms in many patients otherwise severely disabled. Continued research into valve substitutes to treat patients without a native valve option is ongoing. Long-term follow-up with carefully docu- 
mented clinical and diagnostic data with which to demonstrate improvement is essential to evaluate the impact of deep venous valvular reconstruction on patients' disease status.

\section{REFERENCES}

1. Brand FN, Dannenberg AL, Abbott RD, Kannel WB. The epidemiology of varicose veins: the Framingham Study. Am J Prev Med 1988;4:96-101

2. Coon WW, Willis PW, Keller JB. Venous thromboembolism and other venous disease in the Tecumseh community health study. Circulation 1973;48:839-846

3. Baker SR, Stacey MC, Jopp-Mckay AG, et al. Epidemiology of chronic venous ulcers. Br J Surg 1988;78:864-867

4. Flye MW. Venous disorders, the biological basis of disease. In: Sabiston DC, ed. Textbook of Surgery, 15th ed. Philadelphia: WB Saunders; 1996:1581-1593

5. Masuda EM, Kistner RL. Long-term results of venous valve reconstruction: a four to twenty-one year follow-up. J Vasc Surg 1994;19:391-403

6. Budd TW, Meenaghan MA, Wirth J, Taheri SA. Histopathology of veins and venous valves of patients with venous insufficiency syndrome: ultrastructure. J Medicine 1990;21(3-4):181-199

7. O'Donnell TF. Chronic venous insufficiency: an overview of epidemiology, classification, and anatomic considerations. Sem Vas Surg 1988;1(2):60-65

8. Kistner RL, Eklof B, Masuda EM. Deep venous valve reconstruction. Cardiovasc Surg $1995 ; 3: 129-140$

9. Prepared by the Executive Committee, chaired by Andrew N. Nicolaides, of the ad hoc committee, American Venous Forum, 6th Annual Meeting. February 22-25, 1994, Maui, Hawaii. Classification and grading of chronic venous disease in the lower limbs: a consensus statement. In: Gloviczki P, Yao J, ed. Handbook of Venous Disorders. London: Chapman \& Hall; 1996:653-656

10. Porter JM, Moneta GL. Reporting standards in venous disease: an update. J Vasc Surg 1995;21:635-645

11. vanBemmelen PS, Bedford G, Beach K, et al. Quantitative segmental evaluation of venous valvular reflux with duplex ultrasound scanning. J Vasc Surg 1989;10:425-431

12. Summer D. Direct non-invasive tests for the evaluation of chronic venous obstruction and valvular incompetence. In: Gloviczki P, Yao JST, eds. Handbook of Venous Disorders. London: Chapman \& Hall; 1996:130-151

13. Araki CT, Back TL, Padberg FT, et al. The significance of calf muscle pump function in venous ulceration. J Vasc Surg 1994;20:872-877

14. Cordts PR, Hartono C, LaMorte WW, et al. Physiologic similarities between extremities with varicose veins and with chronic venous insufficiency utilizing air plethysmography. Am J Surg 1992;164:260-264

15. Raju S. New approaches to the diagnosis and treatment of venous obstruction. J Vasc Surg 1986;4:42-54

16. Raju S, Fredericks RK, Hudson CA, et al. Venous valve station changes in "primary" and postthrombotic reflux: an analysis of 149 cases. Ann Vasc Surg 2000;14:193-199

17. Kistner RL, Ferris EB, Randhawa G, Kamida C. A method of performing descending venography J Vasc Surg 1986;4:464-468

18. Cheatle TR, Perrin M. Venous Valve repair: early results in fifty-twocases. J Vasc Surg 1994;19:404-413

19. Kistner RL, Sparkuhl MD. Surgery in acute and chronic venous disease. Surg 1979; $85: 31-43$ 
20. Raju S, et al. Durability of venous valve reconstruction techniques for primary and postthrombotic reflux. J Vasc Surg 1996;23:357-367

21. Eriksson I, Almgren B. Influence of the profunda femoris vein on venous hemodynamics of the limb. J Vasc Surg 1986;4:390-395

22. Kistner, RL. Surgical repair of the incompetent femoral vein valve. Arch Surg 1975;110:1336-1342

23. Raju S. Venous insufficiency of the lower limb and stasis ulceration. Ann Surg 1983; 197:688-697

24. Sottiurai VS. Technique in direct venous valvuloplasty. J Vasc Surg 1988;8:646-648

25. Raju S, Fredericks R. Valve reconstruction procedures for nonobstructive venous insufficiency: rationale, techniques, and results in 107 procedures with two- to eight-year follow-up. J Vasc Surg 1988;7:301-310

26. Camilli S, Guarnera G. External banding valvuloplasty of the superficial femoral vein in the treatment of primary deep valvular incompetence. International Angiology 1994;13:218-222

27. Incandela L, Belcaro G, Nicolaides $A N$, et al. Superficial vein valve repair with a new external valve support (EVS). The IMES (International Multicenter EVS Study). Angiology 2000;51(8 Pt 2):S39-S52

28. Kistner RL. Surgical technique of external venous valve repair. The Straub Found Proc 1990;55:15

29. Belcaro G, Nicolaides AN, Ricci A, et al. External femoral vein valvuloplasty with limited anterior plication (LAP): a 10-year randomized follow up study. Angiology 1999; 50:531-536

30. Gloviczki P, Merrell SW, Bower TC. Femoral vein valve repair under direct vision without venotomy: a modified technique with use of angioscopy. J Vasc Surg 1991;14:645-648

31. Eklof BG, Kistner RL, Masuda EM. Venous bypass and valve reconstruction: long-term efficacy. Vasc Med 1998;3:157-164

32. Welch H, McLaughlin RL, O’Donnell TF. Femoral vein valvuloplasty: intraoperative angioscopic evaluation and hemodynamic improvement. J. Vasc Surg 1992;16:694-700

33. Jamieson WG, Chinnick B. Clinical results of deep venous valvular repair for chronic venous insufficiency. Can J Surg 1997;40:294-299

34. Taheri SA, Lazar L, Elias SM, Marchand P. Vein valve transplant. Surgery. 1982;91:28-33

35. O'Donnell TF, Mackey WC, Shepard AD, et al. Clinical, hemodynamic, and anatomic follow-up of direct venous reconstruction. Arch Surg 1987;122:474-482

36. Psathakis ND, Psathakis D. Surgical treatment of deep venous insufficiency of the lower limb. Surg Gyn \& Obs 1988;166:131-141

37. Sun J, Zhang, P. The substitute valve operation on the popliteal vein in the treatment of deep venous incompetence of the lower extremity. Vasc Surg 1987;21:17-27

38. Dalsing MC, Lalka SG, Zukowski AJ, et al. Venous valvular insufficiency: influence of a single venous valve (native and experimental). J Vasc Surg 1991;14:576-587

39. Rosenbloom MS, Schuler JJ, Bishara RA, et al. Early experimental experience with a surgically created, totally autogenous venous valve: a preliminary report. J Vasc Surg 1988;7:642-646

40. Raju S, Hardy J. Technical options in venous valve reconstructions. The Am J Surg 1997;173:301-307

41. Plagnol P, Ciostek P, Grimaud JP, et al. Autogenous valve reconstruction technique for post-thrombotic reflux. Ann Vasc Surg 1999;13:339-342

42. McLachlin AD, Carroll SE, Meads GE, et al. Valve replacement in the recanalized incompetent superficial femoral vein in dogs. Ann Surg 1965;162:446-452

43. Kunlin J, Lengua F, Richard S, et al. Grafting of valvulated veins. J Cardiovascular Surg $1966 ; 7: 520-521$ 
44. Hill R, Schmidt S, Evancho M, et al. Development of a prosthetic venous valve. J Bio Mat Res 1985;19:827-832

45. Taheri SA, Rigan D, Wels P, et al. Experimental prosthetic venous valve. Am J Surg 1988;156:111-114

46. Garcia-Rinaldi R, Revuelta JM, Martinez, MJ, et al. Femoral vein valve incompetence: treatment with a xenograft monocusp patch. J Vasc Surg 1986;3:932-935

47. Burkhart HM, Fath SW, Dalsing MC, et al. Experimental repair of venous valvular insufficiency using a cryopreserved venous allograft aided by a distal arteriovenous fistula. J Vasc Surg 1997;26:817-822

48. Dalsing MC, Raju S, Wakefield TW, Taheri S. A multicenter, phase I evaluation of cryopreserved venous allografts for the treatment of chronic deep venous insufficiency. J Vasc Surg 1999;30:854-866

49. Raju S, Neglan P. The cryo-preserved vein valve: clinical application and early results. Presented at the American Venous Forum, Phoenix, Arizona, February 3-6, 2000 